\title{
La administración pública descentralizada en la evolución constitucional venezolana: especial referencia a los institutos autónomos *
}

\author{
Matheus Inciarte, María Milagros ** \\ Tavares Duarte, Fabiola del Valle ${ }^{\star \star \star}$
}

\section{Resumen}

La Constitución de la República de Venezuela de 1961, se habia convertido desde los años ochenta en un obstáculo para superar la crisis en la cual se encuentra sumergido el país. Centrada en ese propósito, la Asamblea Nacional Constituyente en el año 1999 elaboró varios proyectos de constitución y sancionó la Constitución de la República Bolivariana de Venezuela. La presente investigación, de naturaleza documental, utiliza el método analítico normativo para realizar un estudio comparativo de la Constitución de 1961, las Ideas Fundamentales para la Constitución Bolivariana de la $V$ República de 1999, el Anteproyecto de la Comisión Constitucional de 1999 y de la Constitución vígente, en lo referente a la Administración Pública Descentralizada. Si bien la Constitución de 1961 adolecía de fallas, los restantes dispositivos indicados, aun cuando incluyen ciertos cambios, no logran desvirtuar la problemática generada al interior de la rama descentralizada de la Administración Pública. Se propone una evaluación de tal problemática y la promulgación de una normativa general que regule los aspectos esenciales de la Administración Pública Descentralizada.

Palabras clave: Constitución, Administración Pública Descentralizada, institutos autónomos, empresas del Estado, mecanismos de control.

Recibido: 00-01-17. Aceptado: 00-03-10

* Este trabajo es producto del proyecto de Investigación financiado por el CONDES titulado: Naturaleza e impacto de los servicios autónomos sin personalidad jurídica en la Administración Pública venezolana.

** Abogado. Doctora en Derecho. Investigadora del Instituto de Estudios Políticos y Derecho Público de la Facultad de Ciencias Jurídicas y Políticas de La Universidad del Zulia (LUZ).

** Abogada. Magister Scientiarum en Ciencia Política y Derecho Público, Mención Derecho Pú. blico. Investigadora adscrita al Instituto de Estudios Políticos y Derecho Público de la Facultad de Ciencias Jurídicas y Políticas de LUZ. Email: tavaresfabi@ cantv.net 


\title{
Decentralized Public Administration in the Constitutional Evolution of Venezuela: With Special Attention on Autonomous Institutes
}

\begin{abstract}
The 1961 Constitution of the Republic of Venezuela had become an obstacle in the decade of the nineteen eighties and did not allow the country to overcome the crisis in which it was immersed in relation to the national government. The National Constituent Assembly during the year 1999 elaborated several constitutional projects to solve these problems and approved the Constitution of the Bolivarian Republic of Venezuela. This bibliographical and documentary study utilizes a normative analytical method in a comparative study of the 1961 Constitution, the fundamental ideas behind the 1999 Bolivarian Constitution of the Fifth Republic, the preliminary project of the 1999 Constitutional Commission, and the content of the 1999 constitution, in reference to the decentralization of public administration. If it is true that the 1961 Constitution was defective, the other documents and studies, even though they incorporated certain changes, did not resolve the problems generated in reference to the de-centralization of public administration. Finally, an evaluation of the problems and the promulgation of general norms that regulate essential aspects of decentralized public administration are offered.
\end{abstract}

Key words: Constitution, de-centralized public administration, autonomous institutes, state enterprises, control mechanisms.

\section{Introducción}

La hoy denominada República Bolivariana de Venezuela ha sido objeto de un proceso de profundas reformas en el ámbito constitucional, dicho proceso no sorprende por cuanto se ha convertido en una exigencia de los ciudadanos en la última década. La población venezolana aclama cambios sustanciales circunscritos a la satisfacción del interés general, entre ellos, un mayor acercamiento de la sociedad civil a la toma de decisiones y una adecuada prestación de los servicios públicos. Estos cambios, según el criterio del Presidente Chávez Frías y su tren ejecutivo, debían iniciarse mediante la creación de un nuevo ordenamiento jurídico, cuyo punto de partida lo establece la Constitución de $1999^{1}$.

La República Bolivariana de Venezuela no puede ya identificarse con la Venezuela de mediados de siglo, caracterizada por un Estado profundamente paternalista, dotado de recursos suficientes para abarcar cuanta actividad de interés general existiese. La inadecuada administración de la riqueza, la disminución de

1 Publicada en la Gaceta Oficial de la República de Venezuela N ${ }^{\circ} 36860$, de fecha 30-12-1999 y reimpresa por error material del ente emisor en la Gaceta Oficial de la República Bolivariana de Venezuela $N^{\circ} 5453$ (Extraordinario), de fecha 24-03-2000. 
los ingresos y la escasa potencialidad de la República para atender las demandas colectivas, se tradujeron en la minusvalía de ésta y propiciaron una severa crisis nacional, cuyos principales causantes, en palabras de Brewer Carías, son los partidos políticos, lo cual se constata en las siguientes afirmaciones:

"... a los partidos políticos debemos la implantación de la democracia en nuestro pais, y el desarrollo de la misma se lo debemos a ellos; pero no por ello dejan de ser, también, los responsables de la crisis institucional, que es una crisis del propio sistema político configurado como una democracia de partidos y un Estado de Partidos" (Brewer, 1988: 41-42).

Lejos de continuar con la inútil polémica de atribuir responsabilidades, es oportuno trabajar en forma cohesionada por la reconstrucción del país que a gritos reclama cambios efectivos a objeto de consolidar, con arreglo a lo pautado en el artículo 2 de la Constitución de 1999, "... un Estado democrático y social de Derecho y de Justicia, que propugna como valores superiores de su ordenamiento juridico y de su actuación, la vida, la libertad, la justicia, la igualdad, la solidaridad, la democracia, la responsabilidad social $y$, en general, la preeminencia de los derechos humanos, la ética y el pluralismo político", anhelado por la población, difundido por el propio Ejecutivo Nacional, $y$, en definitiva, constituido en la fórmula capaz de establecer las condiciones necesarias para que los venezolanos alcancen su desarrollo social y espiritual.

El logro de este fin conlleva la adaptación de nuestra Administración Pública a las nuevas realidades nacionales e internacionales, ante las cuales ella no puede continuar impasible, desnaturalizando su objetivo primordial, consistente en proporcionar la mayor cuota de felicidad a sus habitantes, nota esencial de los paises desarrollados. Para poder alcanzar ese propósito, López Nieto y Mallo han destacado la necesidad de impulsar auténticas transformaciones en los ámbitos administrativo y político, según se aprecia a continuación:

"Reforma administrativa y reforma política son expresiones que guardan entre sí intima conexión, por lo condicionante que cada una de ellas resulta para la otra. En efecto, toda reforma política exige y comporta retoques en la Administración, aun en el caso de que ésta hubiera alcanzado cotas muy aceptables, $y$, por el contrario, no puede producirse reforma administrativa de alguna envergadura sin que previamente se produzca una actitud política que la decida y encauce... Y ello sencillamente porque, como tantísimas veces se ha repetido, la Administración no es sino el instrumento de que se sirve el Estado para plasmar en realidad las decisiones politicas.

... Esta función omnicomprensiva, extensísima, puesta al servicio de las decisiones de orden político, ha de constituir el instrumento siempre a punto para cumplir tales decisiones, y no cabe duda que de la perfección de ese instrumento dependerá en buena parte la consecución de los fines del Estado. Por todo ello, una reforma en el orden político no puede olvidar la reforma o puesta a punto de ese elemento instrumental del que tanto va a necesitar. Ninguna acción política, por perfecta que fuera, se vería coronada por el éxito sin una Administración adecuada" (López y Mallo, 1976: 31). 
La Constitución de 1961, las Ideas Fundamentales para la Constitución Bolivariana de la $V$ República, el Anteproyecto de la Comisión Constitucional y la Constitución de la República Bolivariana de Venezuela, reflejan en algunas de sus disposiciones indiferencia con respecto a estas aseveraciones, prueba de ello lo constituyen tanto el desbordamiento de la Administración Pública y sus imprevistas consecuencias como las consecutivas reformas en el último semestre de 1999 de la Ley Orgánica de la Administración Central, incluso antes de la promulgación de la vigente Constitución, las cuales si bien demuestran que las autoridades públicas se han percatado de la existencia de fallas al interior de la Administración Pública, al mismo tiempo revelan el desconocimiento de los problemas neurálgicos y la dificultad para focalizarlos o la escasa voluntad política en descubrirlos y solventarlos. Los mencionados errores deben ser subsanados en un momento, como el actual, en el cual se persigue la materialización de cambios de envergadura capaces de lograr un saneamiento en las bases del aparato administrativo venezolano que garanticen su eficiencia y eficacia y, además, insisten "... en los administrados el consenso, respeto y adhesión propios de la sociedad a la que debemos y podemos aspirar" (Gordillo, 1995: 30).

El presente estudio, sustentado en fuentes bibliográficas-documentales, sigue el método de investigación analítico normativo, basado en un examen conceptual del fenómeno (Pereira: 1998), los fines subjetivos, los valores y las reglas morales y de derecho que lo informan (Manheim y Rich, 1988: 16). De esta manera, se desarrolla el trabajo atendiendo a tres aspectos: en primer lugar, noción de Administración Pública y delimitación de los sub-conjuntos orgánicos que la integran; en segundo lugar, principales normas rectoras de uno de los mencionados sub-conjuntos orgánicos, vale decir, la denominada rama descentralizada de la Administración Pública, contenidas en la Carta Magna de 1961, en los proyectos de reforma constitucional y en la Constitución de 1999; y, en tercer lugar, caracteres fundamentales de la Administración Pública Descentralizada.

\section{Administración Pública en Venezuela}

\subsection{Cuestión preliminar}

En el derecho público se emplea la palabra administración en su acepción estricta, ello es, referida exclusivamente al Estado y las entidades menores de carácter estatal que lo integran (Lares, 1997: 1-2). Dentro de esa acepción estricta debe señalarse que en los ámbitos doctrinal, tanto foráneo (Giannini, Santamaría, Rivero en Peña, 1997b: 14) como nacional (Brewer, Moles en Peña, 1997b: 14; Lares, 1997: 2), y de derecho positivo (artículos 174, 178, 275, 277 de la Constitución de la República Bolivariana de Venezuela), resulta indiscutible el carácter anfibológico del vocablo: Administración Pública, en virtud de que adopta dos sentidos distintos, por un lado, alude al sentido objetivo o material, esto es, a la actividad, tarea o función; $y$, por el otro, al sentido subjetivo u orgánico, es decir, al cuerpo o conjunto de entes $u$ órganos encargados ordinariamente de ejercer la señalada actividad (Lares, 1997: 1-2). 
Hasta la fecha ha sido imposible un consenso doctrinario sobre la delimitación del marco objetivo de la Administración Pública. Esa "... imposibilidad ... ha conducido a un autor del prestigio científico de GIANNINI ... a expresar en forma categórica que ... una caracterización objetiva de la función administrativa no existe" (Giannini en Peña, 1997b: 31). De allí que en esta investigación utilicemos el término Administración Pública en su sentido subjetivo u orgánico.

\subsection{Concepto y Clasificación}

La interpretación concatenada de los artículos $141,144,146,187$, numeral 3, 275 y 277 de la Constitución de la República Bolivariana de Venezuela, revela que el vocablo Administración Pública alude al grupo de entes u órganos "... que constituyen el instrumento de la acción político-administrativa del Estado" (Araujo, 1998: 84).

El mencionado grupo de entes u órganos, se encontraba conformado, hasta la vigencia de la Carta Magna de 1961 , por tres sub-grupos orgánicos: la Administración Pública Central, constituida por una serie de órganos dependientes directamente del Ejecutivo Nacional, entre ellos, el Presidente de la República, el Consejo de Ministros, los Ministros, los Ministerios, los servicios autónomos sin personalidad jurídica y la Procuraduría General de la República; la Administración Pública Descentralizada ${ }^{2}$, represen- tada tanto por entes de derecho público: los establecimientos públicos institucionales (institutos autónomos), los establecimientos públicos corporativos (universidades nacionales autónomas, colegios profesionales, academias nacionales) y los establecimientos públicos asociativos (Banco Central de Venezuela), como por entes de derecho privado: empresas del Estado, asociaciones civiles del Estado y fundaciones del Estado; y, la Administración Pública con Autonomía Funcional, compuesta por la Contraloría General de la República, el Consejo Nacional Electoral, la Fiscalia General de la República y el Consejo de la Judicatura (Corte Primera de lo Contencioso-Administrativo, 1105-80 en Revista de Derecho Público $N^{\circ}$ 03: 104; Corte Primera de lo Contencioso-Administrativo, 28-11-88 en Revista de Derecho Público N ${ }^{\circ} 38: 81$; Brewer, 1994: 117-124, 1997: 27-29; Araujo, 1998: 85-92).

La transcrita clasificación de la Administración Pública ha sido objeto de modificaciones con la publicación de la Constitución de 1999, pues la misma sólo comprende en la actualidad dos sub-conjuntos orgánicos: la Administración Pública Central y la Administración Pública Descentralizada, conformada cada una de ellas por los órganos y entes arriba citados. Ahora bien, la antes denominada Administración Pública con Autonomía Funcional ha desaparecido como tal, en el sentido de que los órganos que la integraban si bien aun existen, ya no forman

2 Esa división obedece a lo que en este trabajo concebimos como Administración Pública Descentralizada lato sensu, conformada por personas jurídicas de carácter estatal (institutos autónomos, universidades nacionales autónomas, Banco Central de Venezuela, empresas del Es- 
parte del Poder Ejecutivo, sino de dos nuevos Poderes: el Poder Ciudadano, ejercido por la Defensoría del Pueblo, el Ministerio Público y la Contraloría General de la República (artículo 273 de la Constitución de la República Bolivariana de Venezuela); $y$, el Poder Electoral, ejercido por el Consejo Nacional Electoral y los organismos subordinados a éste, la Junta Electoral Nacional, la Comisión de Registro Civil y Electoral y la Comisión de Participación Política y Financiamiento (artículo 292 de la Constitución de la República Bolivariana de Venezuela).

Dentro de los subgrupos orgánicos o ramas que comprende la Administración Pública venezolana en el presente, esta investigación se aboca exclusivamente al estudio de la rama descentralizada y en forma privilegiada al examen de los entes de carácter público estatal "... que forman la médula ..." (Brewer, 1997: 28) de la misma: los institutos autónomos, sin obviar algunas referencias a las restantes personas juridicas de derecho público y de derecho privado que la conforman.

\section{Normas rectoras de la Admi-} nistración Pública Descentralizada en el proceso de transformación constitucional venezolano

Durante el período comprendido entre los años 1961 y 1999 la Adminis- tración Pública Descentralizada en Venezuela ha sido sometida a un proceso de transformación de rango constitucional, el cual en el presente estudio se circunscribe principalmente a lo pautado en el artículo 230 de la Constitución de 1961, los artículos 276 y 277 de las Ideas Fundamentales para la Constitución Bolivariana de la V República, el artículo 153 del Anteproyecto de la Comisión Constitucional y los artículos 142 y 300 de la Constitución vigente. Por razones de naturaleza práctica, ello es, para facilitar al lector el conocimiento de los mencionados preceptos, hemos considerado pertinente transcribirlos de manera literal.

\subsection{Artículo 230 de la Constitución de 1961}

"Artículo 230. Sólo por ley, y en conformidad con la ley orgánica respectiva, podrán crearse institutos autónomos.

Los institutos autónomos, así como los intereses del Estado en corporaciones o entidades de cualquier naturaleza, estarán sujetos al control del Congreso ${ }^{3}$, en la forma que la ley establezca".

\subsection{Artículos 276 y 277 de las Ideas Fundamentales para la Constitución Bolivariana de la V República de 1999 "Artículos 276. Sólo por Ley, y en conformidad con la ley orgánica respecti-}

tado, asociaciones civiles del Estado, fundaciones del Estado) y por personas jurídicas de carácter no estatal (colegios profesionales, academias nacionales), según se encuentren o no "... enmarcadas dentro de la estructura organizativa general del Estado" (Brewer, 1984: 239). Por otra parte, la Administración Pública Descentralizada strictu sensu, se encuentra constituida exclusivamente por personas juridicas de carácter estatal.

3 Denominado a partir de la Constitución de la República Bolivariana de Venezuela de 1999: Asamblea Nacional. 
va, podrán crearse institutos autónomos. Los institutos autónomos, así como los intereses del Estado en corporaciones o entidades de cualquier naturaleza estarán sujetos al control del Estado, en la forma que la ley establezca. Se entenderá como instituto autónomo y por tanto sujeto a los requisitos de creación y al régimen de control respectivo, cualquier persona jurídica con objetivo de interés general creada por el Poder Legislativo".

"Artículo 277. El Estado y los entes públicos, en general, tienen las más amplias facultades de control, fiscalización y supervisión sobre el empleo de los fondos públicos, que aporten a Institutos Autónomos, empresas del Estado, sociedades mixtas y otras personas públicas o privadas".

\subsection{Artículo 153 del Anteproyecto de la Comisión Constitucional de 1999}

“Articulo 153. Los institutos autónomos y las empresas públicas podrán crearse solo por ley. Tales instituciones, así como los intereses del Estado en corporaciones o entidades de cualquier naturaleza estarán sujetos al control del Estado, en la forma que la ley establezca.

El Estado y los entes públicos, en general, tienen las más amplias facultades de control, fiscalización y supervisión sobre el empleo de los fondos públicos, que aporte a institutos autónomos, empresas del Estado, sociedades mixtas y otras personas públicas o privadas".

\subsection{Artículos 142 y 300 de la Constitución de la República Bolivariana de Venezuela de 1999}

"Articulo 142. Los institutos autónomos sólo podrán crearse por ley. Tales instituciones, así como los intereses públicos en corporaciones o entidades de cualquier naturaleza, estarán sujetos al control del Estado, en la forma que la ley establezca".

"Artículo 300. La ley nacional establecerá las condiciones para la creación de entidades funcionalmente descentralizadas para la realización de actividades sociales o empresariales, con el objeto de asegurar la razonable productividad económica y social de los recursos públicos que en ellas se inviertan".

Los cambios que a simple vista se observan entre los dispositivos citados, permiten extraer los rasgos o caracteres esenciales de la Administración Pública Descentralizada venezolana y especialmente de los institutos autónomos, los cuales serán discriminados en las páginas siguientes.

\section{Caracteres fundamentales de la Administración Pública Descentralizada en Venezuela}

El análisis exhaustivo del artículo 230 de la Constitución de 1961, los artículos 276 y 277 de las Ideas Fundamentales para la Constitución Bolivariana de la $\checkmark$ República, el artículo 153 del Anteproyecto de la Comisión Constitucional y los artículos 142 y 300 de la Constitución de 
la República Bolivariana de Venezuela, permite clasificar los caracteres fundamentales de la rama descentralizada de la Administración Pública en cuatro grupos, a saber: creación, naturaleza jurídi$\mathrm{ca}$, régimen jurídico y mecanismos de control.

\subsection{Creación}

La Administración Pública Descentralizada, en el pais, según se especificara, se encuentra conformada por personas jurídicas de derecho público y personas jurídicas de derecho privado, cuyos mecanismos tradicionales de creación se limitan, en el primer caso, $a$ un acto del Poder Público; $y$, en el segundo, al cumplimiento de lo pautado en el Código Civil, en el Código de Comercio (Caballero, 1995: 51) o en el Decreto de Reforma Parcial de las Normas sobre las Fundaciones, Asociaciones y Sociedades Civiles del Estado y el Control de los Aportes Públicos a las Instituciones Privadas Similares. Estas consideraciones serán detalladas a continuación, haciendo especial énfasis en la figura de los institutos autónomos.

El artículo 230 de la Constitución de 1961, dispone que sólo por ley podrán crearse institutos autónomos. La redacción del indicado precepto ha motivado el surgimiento de posiciones encontradas, por un lado, la tesis restrictiva ${ }^{4}$ liderada por Andueza sostiene "... que los institutos autónomos están exciuidos de la potestad presidencial, pues su régimen juridico constitucional tiene un tratamiento especial" (Andueza, 1979: 2061); y, por el otro, la tesis amplia esbozada por Brewer Carias y Caballero Ortiz, defiende la inexistencia de una supra reserva legislativa en el prenombrado artículo y admite que el Presidente de la República puede, mediante decreto-ley, crear dichos institutos autónomos (Brewer, 1984: 189-190; Caballero, 1995: 72-73).

Estos últimos autores fundamentan su opinión en los ordinales $8^{\circ}$ y 11 del articulo 190 del derogado Texto Constitucional, los cuales señalan entre las atribuciones y deberes del Presidente de la República, respectivamente, "Dictar medidas extraordinarias en materia económica o financiera cuando así lo requiera el interés público y haya sido autorizado para ello por ley especial" y "Decretar en caso de urgencia comprobada, durante el receso del Congreso, la creación y dotación de nuevos servicios públicos, o la modificación o supresión de los existentes, previa autorización de la Comisión Delegada".

Consideramos que los comentarios de Brewer Carías y Caballero Ortíz resultan válidos a la luz de la Carta Magna de 1961, pues haciendo uso de la atribución contenida en el artículo 190, ordinal $8^{\circ}$, el Presidente de la República, entre los años 1974 y 1975, por decreto ley con habilitación legislativa transformó el Fondo Nacional del Café y del Cacao, configurado originalmente como servicio autónomo sin personalidad jurídica, en dos institutos autónomos, materia que según la indicada Carta corresponde en principio al legislador.

4 Esta tesis parece ser la inspiración del artículo 276 de las Ideas Fundamentales para la Constitución Bolivariana de la $V$ República. 
más variados, sobre todo en el organizativo (Ley Orgánica de la Administración Central), asi como incluso en la esfera estatutaria (Ley de Carrera Administrativa)" (Voto Salvado/Corte Suprema de Justicia/Corte Plena: 09-11-99 en Pierre Tapia, 1999: 323).

De lo antes expuesto, se desprende que el principio de la reserva legal, consagrado en la Constitución de 1961, en el Anteproyecto de la Comisión Constítucional de 1999 y en la Constitución vigente, carece de rigidez, por cuanto el Ejecutivo siempre ha podido invadir la reserva legal mediante la emisión de decretos leyes con habilitación legislativa, lo cual ha sido agudizado en el Texto Constitucional de la República Bolivariana de Venezuela de 1999, pues al eliminarse los IImites atinentes a la exigencia del interés público y a la materia económica y financiera, el Presidente de la República en ausencia de circunstancias anormales puede configurar no sólo institutos autónomos sino cualquier otro tipo de personas jurídicas, tanto de derecho público como de derecho privado.

El artículo 190, ordinal 11, ubicado en el Título VI, Del Poder Ejecutivo Nacional, Capitulo II, De las atribuciones del Presidente de la República, de la Constitución de 1961 mantiene de manera similar su redacción y contenido en la evolución constitucional iniciada en el año de 1999. No obstante, creemos prudente resaltar que el mismo tanto en los proyectos constitucionales como en la Constitución vigente ha sido repartido en dos dispositivos, desarrollados dentro de las atribuciones de la Comisión Delegada, a saber: artículos 327 y 328 , numeral 5 , de las Ideas Fundamentales para la Constitu- ción Bolivariana de la V República, artículos 226 y 227, numeral 6, del Anteproyecto de la Comisión Constitucional y articulos 195 y 196, numeral 6, de la Constitución Bolivariana. De allí, se infiere que en el presente el Ejecutivo puede continuar con la práctica de crear institutos autónomos en virtud de decretos leyes sin habilitación legislativa.

En este orden de ideas, dentro de la categoría de establecimientos públicos corporativos, debemos resaltar la forma de creación de sus personas jurídicas públicas de carácter estatal y de sus personas jurídicas públicas de carácter no estatal. En el primer grupo, destacan las universidades nacionales autónomas, creadas de conformidad con lo pautado en los artículos 8 y 12 de la Ley de Universidades, donde se exige un acto de individualización y singularización concreto, es decir, un decreto para que adquieran personalidad juridica con la publicación del mismo en la Gaceta Oficial (Corte Primera de lo Contencioso-Administrativo, 21 03-84 en Araujo, 1998: 88). En el segundo grupo, resaltan los colegios profesionales, creados en virtud de una ley, "... por tal circunstancia, adquieren la personalidad jurídica ope legis ..." (Caballero, 1995: 47); y las academias nacionales, constituidas tanto por ley como por decreto (Lares, 1997: 639).

En el género de establecimientos públicos asociativos, ubicamos al Banco Central de Venezuela, creado por mandato expreso de la Ley del 8 de septiembre de 1939, cuya más reciente reforma data del 4 de diciembre de 1992 (artículo $1^{\circ}$, Ley del Banco Central de Venezuela; Brewer, 1997: 28; Lares, 1997: 671-672; Peña, 1997a: 83). 
En cuanto a los entes de derecho privado de la Administración Pública Descentralizada, identificamos: las empresas del Estado, cuya constitución se lleva a cabo básicamente mediante al cumplimiento del procedimiento contemplado en el Código de Comercio; las asociaciones civiles del Estado y las fundaciones del Estado, ambas configuradas según lo establecido en el Código Civil y en el Decreto de Reforma Parcial de las Normas sobre las Fundaciones, Asociaciones y Sociedades Civiles del Estado y el Control de los Aportes Públicos a las Instituciones Privadas Similares (Brewer, 1984: 246, 1994: 121).

Las descritas son las formas tradicionales utilizadas para dar nacimiento a esas personas juridicas de la Administración Pública Descentralizada, hasta la vigencia de la Constitución de 1961. Sin embargo, una vez publicada la Carta Magna de 1999, no debe extrañar la creación de las citadas personas a través de decretos con rango y valor de ley, emanados del Presidente de la República, en virtud de la ya explicada interpretación concatenada de los artículos 236 , numeral 8, y 203, ejusdem.

En otro orden de ideas, el artículo 230 de la Constitución derogada y el articulo 276 de las Ideas Fundamentales para la Constitución Bolivariana de la $\mathrm{V}$ República destacan la necesidad de que los institutos autónomos sean creados en conformidad con la ley orgánica respectiva. El texto de ambas disposiciones, sugiere la formulación de las siguientes interrogantes: ¿esa ley alude a una ley orgánica de institutos autónomos?, ¿esa ley se refiere a una ley orgánica de la Administración Pública Descentralizada?
Si la respuesta a la primera de las interrogantes fuere afirmativa tendría que acogerse la tesis propuesta por Brewer Carias, cuando expresa: “... b) Su organización con arreglo a lo dispuesto en la ley orgánica que sobre institutos autónomos deberá dictarse y a la cual deben adaptarse todos los institutos autónomos ..." (Brewer, 1994: 118). Discrepamos de este criterio, por cuanto el mismo conllevaría a la promulgación de una pluralidad de leyes rectoras de cada uno de los entes integrantes de la rama descentralizada de la Administración Pública.

En el caso de ser positiva la respuesta a la segunda de las preguntas planteadas, habría que aceptar que esas normas hacen referencia a la tan discutida y hasta el presente no sancionada Ley Orgánica de la Administración Pública Descentralizada. Criterio que defendemos atendiendo a razones teóricas, prácticas y constitucionales: por un lado, resulta innecesario que el Poder Legislativo dicte una ley para cada persona jurídica de la Administración Pública Descentralizada, siendo más prudente la sanción de un sólo cuerpo normativo que las regule; por el otro, si el Poder Legislativo ha encontrado serias dificultades para dictar una de esas leyes, dicha dificultad aumentaría si tuviese que dictar una ley para cada figura subjetiva; $y$, por último, de acuerdo a lo dispuesto en el artículo 300 y la disposición transitoria cuarta, numeral 5 , de la Constitución vigente, los cuales exigen, respectivamente, que los requisitos para la creación de los entes funcionalmente descentralizados, destinados a la realización de actividades sociales y empresariales, sean establecidos en una ley de carácter nacional; y, la 
aprobación, dentro del primer año contado a partir de la instalación de la Asamblea Nacional, de la legislación relativa a la Administración Pública Nacional.

De alli, se deduce que el constituyente venezolano, finalmente, ha comprendido la necesidad de sancionar la normativa que se constituya en el marco regulador de la rama descentralizada de la Administración Pública, con el propósito de unificar criterios en cuanto a la configuración y al funcionamiento de cada uno de sus entes. Asimismo, el constituyente ha entendido que ello sólo es viable mediante un proceso de reformulación de la legislación atinente a la Administración Pública Nacional.

\subsection{Naturaleza y régimen jurídicos}

El artículo 230 de la Constitución de 1961 , sus equivalentes en los proyectos de reforma constitucional y en la Constitución vigente determinan las personas de naturaleza jurídica pública y las personas de naturaleza jurídica privada, diferentes a la Pepública, que conforman a la Administración Pública Descentralizada en Venezuela. Esta circunstancia responde a la necesidad de que los mencionados entes conserven su individualidad patrimonial, financiera y presupuestaria.

El elemento personalidad jurídica involucra efectos trascendentes que aun los adversarios del mismo, como nota esencial de la Administración Pública Descentralizada, se han visto forzados a reconocer (Ariño, 1972; Sayagués,
1959). Sobre el particular, Caballero Ortíz destaca:

"1.La personalidad jurídica implica ser sujetos de derechos y obligaciones, capaces de adquirir, demandar y ser demandados $y$, en general, realizar actos jurídicos frente a terceros.

2. La personalidad jurídica implica la existencia del ente, independientemente de los miembros que la integran. Se establece así una limitación y separación de responsabilidades.

3. Existencia de un patrimonio al cual cabe referir la responsabilidad.

4. Ruptura de los nexos de jerarquía $^{5}$, principio que mantiene su valor no obstante la consagración legislativa de un recurso jerárquico impropio con respecto a una categoría concreta de entes descentralizados funcionalmente: los institutos autónomos.

5. Sometimiento a un derecho especial, singular o específico" (Caballero, 1995: 32-33).

En este sentido, es pertinente analizar uno de los temas más controvertidos en la doctrina, ello es, el criterio de distinción entre las personas jurídicas de derecho público y las personas juridicas de derecho privado. Sin ánimos de teorizar sobre el mencionado asunto y desconocer los incalculables esfuerzos doctrinales y jurisprudenciales por trazar las lineas divisorias entre ambos tipos de personas jurídicas, consideramos que el carácter público de la personalidad de una figura jurídica surge forzosamente de los denominados índices de reconocimiento

5 Sobre esta ruptura existe discrepancia en el ámbito doctrinal, lo cual se profundiza en el punto atinente a los mecanismos de control. 
o de publicidad, no siendo indispensable para la calificación de un ente como público la concurrencia de todos y cada uno de ellos (Alessi; Auby; De Laubadere; Galgano; Zanobini en Boscán, 1982: 56).

La presente teoría de los índices de reconocimiento o de publicidad ha sido acogida por la sentencia de principios de la antes denominada Corte Suprema de Justicia, en Sala Político-Administrativa ${ }^{6}$, de fecha 5 de octubre de 1970, la cual entiende como criterio para clasificar a las personas jurídicas en públicas y privadas al predominio de ciertas características. El fallo en cuestión, luego de resaltar que la determinación de las citadas características ha constituido en los últimos años uno de los problemas del derecho administrativo, señala que en la primera categoría de personas jurídicas concurren en forma determinante algunos de los siguientes rasgos distintivos: deben su existencia a un acto emanado de un órgano competente del Poder Público; tienen por objeto un fin de interés general; su patrimonio proviene del erario público; las normas jurídicas que regulan su organización y funcionamiento son de naturaleza pública; sus planes y programas, al igual que su competencia territorial o funcional, son establecidos y delimitados por los órganos del Poder Público; se encuentran obligadas a someter sus presupuestos de gastos o inversiones y a rendir cuentas de su gestión al Poder Legislativo o al Poder Ejecutivo; están exentas del pago de contribuciones nacionales y pueden gozar de varias prerrogativas que la ley concede al Estado; los be- neficios 0 utilidades que obtengan, generalmente, deben ser reinvertidos en la expansión de sus actividades, la renovación de sus equipos o el mejoramiento de los servicios que ofrecen (Corte Suprema de Justicia/Sala Político-Administrativa: 0510-70 en Boscán, 1982: 58).

De la sentencia transcrita, se infiere que ante la inexistencia de los rasgos distintivos en ella descritos, se está en presencia de una persona jurídica de derecho privado. Por su parte, Peña Solís influenciado por un grupo de autores italianos al cuestionar la indicada teoria, constata que la existencia de todos o casi todos los índices de reconocimiento o de publicidad pueden estar presentes en entes que nadie dudaría en considerarlos como de derecho privado. De tal manera, el citado autor expresa:

“... en cuanto al CONTROL ADMINISTRATIVO, precisaron que existia infinidad de entes privados que estaban sometidos al control del Estado o de sus entes instrumentales, citándose como emblemático el caso de los bancos y otras instituciones financieras. En lo atinente a la POTESTAD DE IMPERIO, la doctrina demostró que no era privativa de los entes públicos, en virtud de que existian personas jurídicas de derecho privado que también la detentaban, por ejemplo las empresas concesionarias de servicios públicos, a las cuales se les confiere el ejercicio de la función de policía administrativa en dicho servicio, pudiendo llegar hasta imponer sanciones pecuniarias. En cuanto al FIN PUBLICO,

6 A partir de la Constitución de la República Bolivariana de Venezuela de 1999: Tribunal Supremo de Justicia/Sala Políticoadministrativa. 
se alegó que existían entes reputados como públicos cuyo fin dista bastante, 0 nada tiene que ver con los fines esenciales del Estado, verbigracia los denominados entes públicos comerciales e industriales del Derecho Francés. En lo atinente al ORIGEN, se indicó la existencia de entes públicos de origen privado. Sería el caso, en otros Ordenamientos, de las denominadas empresas públicas" (Peña, 1997a: 69).

Esta disparidad de criterios en los ámbitos jurisprudencial y doctrinal a los fines de identificar a las personas jurídicas públicas y a las personas jurídicas privadas se matizaría con la promulgación de una ley orgánica de la Administración Pública Descentralizada, detallando en su articulado una $u$ otra naturaleza jurídica de los entes que la conforman, lo cual estimamos posible en virtud de una interpretación concatenada del artículo 300 y de la disposición transitoria cuarta, numeral 5, de la Constitución de la República Bolivariana de Venezuela de 1999. Ello, a su vez, frenaria el desorden que se observa al interior de esa rama de la Administración Pública como consecuencia del conferimiento, por parte de la doctrina y la jurisprudencia, a una misma persona jurídica carácter público o privado, tal es el caso típico de las empresas del Estado (Viloria, 1983; González, 1987; Lares, 1997; Corte Suprema de Justicia/Sala Político-Administrativa: 02-12-98 en Pierre, 1998, No 12).

El constituyente en el Anteproyecto de la Comisión Constitucional, se percata de las consecuencias de ese otorgamiento de naturaleza jurídica tanto pública como privada a las "empresas públicas", pues al exigir en su artículo 153 la necesi- dad de su configuración por medio de ley, se infiere la intención de calificarlas con el carácter de personas jurídicas de derecho público, lo cual si bien responde al principio general de que toda entidad pú. blica debe ser creada por ley, el mismo no resulta ser un elemento contundente para distinguir una $u$ otra clase de personas, siendo necesario recurrir a los restantes índices de publicidad. En tal sentido, Peña Solís, al analizar el supuesto concreto del Banco Industrial de Venezuela, ente privado constituido por ley, destaca que "... no toda persona jurídica que se origine en una Ley, necesariamente detenta naturaleza pública ..." (Peña, 1997a: 85).

Por otra parte, el artículo 153 del Anteproyecto de la Comisión Constitucional de 1999 no alude a las sociedades mercantiles en las cuales el Estado tiene participación decisiva mediante una terminología unívoca, sino que, por el contrario, las denomina indistintamente empresas públicas y empresas del Estado, haciendo, además, mención expresa a las sociedades mixtas, lo que conlleva a plantearse si estas últimas se corresponden con las citadas empresas públicas o empresas del Estado. Esa pluralidad terminológica acentúa la desorganización dentro de la Administración Pública Descentralizada y una de las formas de restringirla pudiera encontrarse en el empleo de una única expresión para identificar a un mismo instituto jurídico. Esta discusión es irrelevante a la luz del artículo 142 de la Constitución actual, pues no alude de forma directa a las citadas empresas, las que se engloban en la expresión "intereses públicos en corporaciones o entidades de cualquier naturaleza ...". 
En cuanto al régimen jurídico propio y común de la Administración Pública en general, y, por ende, de la Administración Pública Descentralizada, debemos precisar que éste es el derecho administrativo, sin embargo, ello no equivale a afirmar, en criterio de Brewer Carías, que el mismo sea a: los institutos autónomos, las universidades nacionales autónomas, los colegios profesionales, las academias nacionales, el Banco Central de Venezuela, las empresas del Estado, las asociaciones civiles del Estado y las fundaciones del Estado un derecho exclusivo y excluyente.

"No es exclusivo, pues ... el derecho administrativo es comúnmente aplicable a los particulares ... Y no es excluyente porque el derecho administrativo no es el único derecho aplicable a la $\mathrm{Ad}$ ministración Pública. Esta, en todos los campos antes señalados que conforman el objeto del derecho administrativo, también se rige por el derecho privado .... unas veces más, otras veces menos, dependiendo de las épocas históricas y de las politicas públicas; y que siempre conforman el derecho supletorio ante la ausencia de principios generales del propio derecho administrativo ... En todo caso, siempre ha habido una interaplicación del derecho administrativo y del derecho privado a la Administración Pública... " (Brewer, 1996: 25).

Esta tesis doctrinal es defendida, igualmente, por la sentencia de fecha 18 de julio de 1985 de la entonces llamada Sala Político-Administrativa de la Corte Suprema de Justicia, en el caso Leopoldo Díaz Bruzual - Banco Central de Venezuela, por cuanto al determinar el régi- men jurídico aplicable al referido Banco declara:

"Sostener que un hecho de la vida social está regido exclusivamente por un determinado sector del derecho público 0 del derecho privado es algo que no se conforma con la realidad ni con los principios científicos. El derecho es una unidad. Según varíen las circunstancias, una misma persona o una misma cosa puede ser objeto de la aplicación de una norma de derecho público o de una de derecho privado o, también, y al misma (sic) tiempo, de ambos tipos de disposiciones" (Corte Suprema de Justicia / Sala Político-Administrativa: 18-07-85 en Brewer y Ortiz, 1996: 554).

Se observa en los ámbitos doctrinal y jurisprudencial el reconocimiento de la aplicación de reglas de derecho público y reglas de derecho privado a cualquier persona jurídica, atendiendo a “... la naturaleza del acto efectuado" (Corte Suprema de Justicia/Sala Político-Administrativa: 18-07-85 en Brewer y Ortiz, 1996: 555), lo cual se hace extensible a las personas jurídicas pertenecientes a la Administración Pública Descentralizada, enunciadas en el artículo 230 de la Constitución de 1961, los artículos 276 y 277 de las ldeas Fundamentales para la Constitución Bolivariana de la V República, el artículo 153 del Anteproyecto de la Comisión Constitucional y los artículos 142 y 300 de la Constitución vigente.

Para finalizar la discusión sobre la naturaleza jurídica y el régimen jurídico de las diversas entidades integrantes de la Administración Pública Descentralizada venezolana, estimamos importante reconocer la íntima conexión existente en- 
tre ambos caracteres, pues la reunión de los mismos permite definir a dicha rama de la Administración Pública como una estructura administrativa heterogénea, al estar conformada por personas de distinta naturaleza y de diferente régimen. No obstante, ".... el carácter de las normas que regulan la actuación de un ente, nunca puede servir para determinar su naturaleza, pues en otro caso habria que convenir que la Administración Pública deja de ser pública cuando se somete al Derecho Privado ...." (De Miguel García en Caballero, 1995: 45).

\subsection{Mecanismos de control}

El control es una figura propia del Estado de Derecho, cuyo fundamento se encuentra en el principio de legalidad, ello es, en la necesidad de garantizar que la actuación del Estado y de la Administración Pública se ajusten a la Constitución y al resto del ordenamiento jurídico, a fin de frenar la arbitrariedad estatal (Rondón, 1995: 146; Peña, 1997a: 231).

El artículo 230 de la Constitución recientemente derogada establecía, con respecto a las personas jurídicas de la Administración Pública Descentralizada, un control circunscrito al ejercido por el Congreso, el cual ha sido denominado control legislativo. El constituyente de 1999, tanto en los articulos 276 y 277 de las Ideas Fundamentales para la Constitución Bolivariana de la V República como en el articulo 153 del Anteproyecto de la Comisión Constitucional y en el artículo 142 de la Constitución de la República Bolivariana de Venezuela, deja abierta la posibilidad de que otros órganos del Poder Público desplieguen sobre los mencionados entes controles de variada naturaleza, a título de ejemplo: el control judicial, el control fiscal y el control de tutela (Caballero, 1995: 229-273; Peña, 1997a: 231-243; Rachadell, 1985: 247-312).

En este orden de ideas, observamos en los citados proyectos constitucionales la consagración de un particuiar control, cuyo ámbito de aplicación lo constituyen los fondos públicos que aporten "El Estado y los entes públicos, ... a institutos autónomos, empresas del Estado, sociedades mixtas y otras personas públicas o privadas". Esta consagración encuentra su fundamento en la no correspondencia entre la realidad venezolana de 1961 y la Venezuela de comienzos del siglo XXI, caracterizada por el recrudecimiento de la corrupción, lo cual exige una fiscalización más operativa del patrimonio público, que el proyectista pretende garantizar otorgándole rango constitucional. La referencia expresa al control sobre los fondos públicos desaparece en la Constitución de 1999, sin contribuir con elio a mermar "... la extensión, complejidad y variedad de las técnicas de control ..." (Giannini en Rondón, 1995: 146) que pesan sobre las personas jurídicas de la Administración Pública Descentralizada. Lo indicado permite preguntarnos con respecto a dichas técnicas de control: ¿configuran el medio propicio para garantizar que los entes descentralizados funcionalmente no se desvíen de los fines del Estado 0 , por el contrario, constituyen un factor limitante para la consecución de los mismos? Con el objeto de dar respuesta a la interrogante planteada, es preciso citar a Brewer Carías, al señalar que "La autonomía, en todo caso, está en una relación inversa con el control: a ma- 
tre ambos caracteres, pues la reunión de los mismos permite definir a dicha rama de la Administración Pública como una estructura administrativa heterogénea, al estar conformada por personas de distinta naturaleza y de diferente régimen. No obstante, ".... el carácter de las normas que regulan la actuación de un ente, nunca puede servir para determinar su naturaleza, pues en otro caso habría que convenir que la Administración Pública deja de ser pública cuando se somete al Derecho Privado ...." (De Miguel García en Caballero, 1995: 45).

\subsection{Mecanismos de control}

El control es una figura propia del Estado de Derecho, cuyo fundamento se encuentra en el principio de legalidad, ello es, en la necesidad de garantizar que la actuación del Estado y de la Administración Pública se ajusten a la Constitución y al resto del ordenamiento jurídico, a fin de frenar la arbitrariedad estatal (Rondón, 1995: 146; Peña, 1997a: 231).

El artículo 230 de la Constitución recientemente derogada establecia, con respecto a las personas jurídicas de la $\mathrm{Ad}$ ministración Pública Descentralizada, un control circunscrito al ejercido por el Congreso, el cual ha sido denominado control legislativo. El constituyente de 1999, tanto en los artículos 276 y 277 de las Ideas Fundamentales para la Constitución Bolivariana de la V República como en el artículo 153 del Anteproyecto de la Comisión Constitucional y en el artículo 142 de la Constitución de la República Bolivariana de Venezuela, deja abierta la posibilidad de que otros órganos del Poder Público desplieguen sobre los mencionados entes controles de variada naturaleza, a título de ejemplo: el control judicial, el control fiscal y el control de tutela (Caballero, 1995: 229-273; Peña, 1997a: 231-243; Rachadell, 1985: 247-312).

En este orden de ideas, observamos en los citados proyectos constitucionales la consagración de un particular control, cuyo ámbito de aplicación lo constituyen los fondos públicos que aporten "El Estado y los entes públicos, ... a institutos autónomos, empresas del Estado, sociedades mixtas y otras personas públicas o privadas". Esta consagración encuentra su fundamento en la no correspondencia entre la realidad venezolana de 1961 y la Venezuela de comienzos del siglo XXI, caracterizada por el recrudecimiento de la corrupción, lo cual exige una fiscalización más operativa del patrimonio público, que el proyectista pretende garantizar otorgándole rango constitucional. La referencia expresa al control sobre los fondos públicos desaparece en la Constitución de 1999, sin contribuir con ello a mermar "... la extensión, complejidad y variedad de las técnicas de control ..." (Giannini en Rondón, 1995: 146) que pesan sobre las personas jurídicas de la Administración Pública Descentralizada. Lo indicado permite preguntarnos con respecto a dichas técnicas de control: ¿configuran el medio propicio para garantizar que los entes descentralizados funcionalmente no se desvien de los fines del Estado o, por el contrario, constituyen un factor limitante para la consecución de los mismos? Con el objeto de dar respuesta a la interrogante planteada, es preciso citar a Brewer Carías, al señalar que "La autonomía, en todo caso, está en una relación inversa con el control: a ma- 
La imposibilidad de separar "... por una línea de demarcación precisa y categórica" tales controles (De Laubadere en Cabailero, 1995: 220) es reafirmada en el artículo 37, numeral 12, del Decreto con rango y fuerza de Ley Orgánica de la Administración Central de 1999, al establecer entre las competencias comunes de los Ministros con Despacho el "Ejercer sobre los institutos autónomos, fundaciones, asociaciones y sociedades civiles del Estado, las funciones de coordinación y control que les corresponda conforme a este Decreto Ley, las Leyes especiales de creación y los demás instrumentos jurídicos respectivos ...". El artículo en cuestión alude a la figura juridica del control, sin especificar su tipo o modalidad, lo cual nos permite dudar sobre el particular, pues según la concepción clásica el control de tutela sólo opera sobre los entes de derecho público de la Administración Pública Descentralizada, $y$ es el caso que nos encontramos ante un control cuyo ámbito subjetivo lo constituyen también los entes de derecho privado de la Administración Pública Descentralizada.

En consecuencia, para poder afirmar que el nombrado artículo 37 , numeral 12 , consagra un control de tutela tendriamos que aceptar una nueva posición en el derecho positivo venezolano en cuanto a su conceptualización, al postular "... su extensión a los entes privados estatales" (Peña, 1997a: 240). Esta tesis ya había sido defendida por la entonces Corte Suprema de Justicia en Sala Plena, en una sentencia aislada y atípica de fecha 6 de diciembre de 1989 , al declarar la procedencia del control de tutela del Instituto
Nacional de la Cultura sobre la Fundación Orquesta Sinfónica de Venezuela (Peña, 1997a: 79-81).

Lejos de pretender inclinarnos a favor o en contra de esta última posición, esperamos haber recalcado la incertidumbre y la confusión existente en materia de controles alrededor de la Administración Pública Descentralizada en el pais, la cual revela la necesidad, tantas veces reiterada, de promulgar un instrumento de rango legal que regule éste y otros trascendentales aspectos de dicha Administración Pública, frenando asi la anarquía propia de ciertas leyes de creación de institutos autónomos y demás establecimientos públicos y de algunos estatutos de las empresas del Estado, en los que se estipulan una distinta tipologia e intensidad de controles para entes similares e, incluso, para una misma persona jurídica.

\section{Conclusiones}

La Administración Pública Descentralizada en Venezuela ha sido objeto de profundas críticas en cuanto a su creación, las formas adoptadas para su configuración, el régimen jurídico aplicable, el control que se ejerce sobre la misma, entre otras cuestiones significativas. Estos aspectos han sido objeto de constante análisis en los ámbitos doctrinal y jurisprudencial, el cual, en alguna medida, se refieja en las Ideas Fundamentales para la Constitución Bolivariana de la V República, el Anteproyecto de la Comisión Constitucional y la Constitución de la República Bolivariana de Venezuela de 1999 , pero $\sin$ vislumbrarse cambios sus- 
tanciales que orienten a la Administración Pública a la pronta y eficiente consecución de sus altos fines.

La ausencia de esas transformaciones encuentra su principal fundamento en la persistencia de un marcado intervencionismo por parte del Estado, el cual según los términos consagrados en la Carta Magna de la República Bolivariana de Venezuela es federal descentralizado, pero en realidad se proyecta como un Estado centralizado que, para organizar y preservar su poder, crea figuras jurídicas (institutos autónomos, universidades nacionales autónomas, colegios profesionales, academias nacionales, Banco Central de Venezuela, empresas del Estado, asociaciones civiles del Estado y fundaciones del Estado) y mecanismos de control (legislativo, judicial, fiscal, de tutela, entre otros), cuya proliferación lejos de solventar la crisis en la que se encuentra inmersa la Administración Pública la profundiza.

Esta inadecuada práctica no se considera la solución al problema, por cuanto la misma debe buscarse al interior de la Administración Pública Descentralizada, siguiendo un proceso de fases interdependientes: en primer lugar, la evaluación de esa rama de la Administración; $y$, en segundo lugar, la promulgación de la ley orgánica de la Administración Pública Descentralizada, que debe erigirse en la norma rectora de las formas jurídicas de los entes descentralizados funcionalmente y el control desarrollado sobre éstos.

Ese proceso de fases interdependientes no puede ser obviado en un momento caracterizado por la reconstruc- ción del ordenamiento jurídico, con el propósito de garantizar que tanto la nueva Constitución venezolana como las demás leyes sean el producto de un debate público, libre, crítico (Gordillo, 1995: 32), y se adapten a las transformaciones que exige el sistema socio-político y la Administración Pública.

\section{Bibliografía citada}

Andueza, J. (1979). "Las Potestades Normativas del Presidente de la República". Estudio sobre la Constitución. Libro Homenaje a Rafael Caldera. T. IV. Universidad Central de Venezuela. Caracas.

Araujo, J. (1998). Tratado de Derecho Administrativo Formal. Vadell - Hermanos Editores. Caracas.

Ariño, G. (1972). La Administración Institucional: Bases de su Régimen Jurídico. Instituto de Estudios Administrativos. Madrid.

Boscán, I. (1982). "Consideraciones sobre la Naturaleza Juridica de Petróleos de Venezuela", Revista de Derecho Público. $N^{\circ} 9$. Editorial Jurídica Venezolana. Caracas.

Brewer, A. (1984). Fundamentos de la Administración Pública. Editorial Jurídica Venezolana. Caracas.

Brewer, A. (1988). Problemas del Estado de Partidos. Editorial Juridica Venezolana. Caracas.

Brewer, A. (1994). Principios del Régimen Jurídico de la Organización Administrativa Venezolana. Colección Estudios Jurídicos N49. Editorial Jurídica Venezolana. Caracas.

Brewer, A. (1996). "La Interaplicación del Derecho Público y del Derecho Privado a la Administración Públlca y el Proceso de Huida y Recuperación del Derecho 
Administrativo". Segundas Jornadas Internacionales de Derecho Administrativo Allan Randolph Brewer Carías. Fundación Estudios de Derecho Administrativo. Caracas.

Brewer, A. (1997). El Derecho Administrativo y la Ley Orgánica de Procedimientos Administrativos. Editorial Juridica Venezolana, Caracas.

Brewer, A. (2000). La Constitución de 1999. Editorial Arte. Caracas.

Brewer, A. y Ortiz, L. (1996). Las Grandes Decisiones de la Jurisprudencia Con* tencioso Administrativa (19611996). Editorial Jurídica Venezolana. Caracas.

Caballero, J. (1995). Los Institutos Autónomos. Editorial Jurídica Venezolana. Caracas.

Entrena, R. (1988) .Curso de Derecho Administrativo. V. 1/2. Editorial Tecnos. Madrid.

González, F. (1987). Derecho Administrativo Español. T. I. Universidad de Navarra. Pamplona.

Gordillo, A. (1995). La Administración Paralela. Cuadernos Civitas. Madrid.

Lares, E. (1997), Manual de Derecho Administrativo. Universidad Central de Venezuela -Facultad de Ciencias Jurídicas y Politicas. Caracas.

López, F. y Mallo. (1976). "La Reforma Administrativa como Instrumento de la Reforma Política". Revista Documenta* ción Administrativa. Presidencia del Gobierno Secretaría General Técnica. Madrid.

Manheim, J. y Rich, R. (1988). Análisis Político Empírico. Métodos de Investigación en Ciencia Política. Editorial Alianza. Madrid.

Peña, J. (1997a). Lineamientos de Derecho Administrativo. La Organización Administrativa Venezolana. $V$. I.
Universidad Central de Venezuela Facultad de Ciencias Juridicas y Políticas. Caracas.

Peña, J. (1997b). Lineamientos de Derecho Administrativo. El Derecho Administrativo y sus Fuentes. V. II. Universidad Central de Venezuela - Facultad de Clencias Jurídicas y Politicas. Caracas.

Pereira, V. (1998). Notas de Clases. (mimeo).

Pierre, O. (1998). Jurisprudencia de la Corte Suprema de Justicia. Repertorio Mensual de Jurisprudencia No 12. Editorial Jurídica Pierre Tapia. Caracas.

Pierre, O. (1999). Jurisprudencia de la Corte Suprema de Justicia. Repertorio Mensual de Jurisprudencia $N^{\circ} 11 . T$. I. Editorial Juridica Pierre Tapia. Caracas.

Rachadell, M. (1985). Lecciones sobre Presupuesto Público. Colección Estudios Jurídicos $N^{\circ}$ 28. Editorial Jurídica Venezolana. Caracas.

República Bolivariana de Venezuela. Asamblea Nacional Constituyente (2000). Constitución de la República Bolivariana de Venezuela. Gaceta Oficial de la República Bolivariana de Venezuela $N^{\circ} 5453$ (Extraordinario). 2403-2000. Caracas.

República de Venezuela. Asamblea Nacional Constituyente (1999). Ideas Fundamentales para la Constitución Bolivariana de la V República. Caracas.

República de Venezuela. Asamblea Nacional Constituyente (1999). Anteproyecto de la Comisión Constitucional. Caracas.

República de Venezuela. Asamblea Nacional Constituyente (1999). Constitución de la República Bolivariana de Venezuela. Gaceta Oficial de la República de Venezuela $\mathrm{N}^{\circ} 36860$. 30-121999. Caracas. 
República de Venezuela. Congreso Nacional. (1961). Constitución de Venezuela. Gaceta Oficial de la República de Venezuela $N^{\circ} 662$ (Extraordinario). 2301-1961. Gaceta Oticial de la República de Venezuela $N^{\circ} 3357$ (Extraordinario). 02-03-1984. Caracas.

Repüblica de Venezuela. Congreso Nacional (1970). Ley de Universidades. Gaceta Oficial de la República de Venezuela $N^{\circ} 1429$ (Extraordinario). 0809-1970. Caracas.

República de Venezuela. Congreso Nacional (1992). Ley del Banco Central de Venezuela. Gaceta Oficial de la República de Venezuela $\mathrm{N}^{\circ} 35106$. 0412-1992. Caracas.

República de Venezuela. Presidente de la República (1985). Decreto $\mathrm{N}^{\circ} 677$ de Reforma Parcial de las Normas sobre las Fundaciones, Asociaciones y Sociedades Civiles del Estado y el Control de los Aportes Públicos a las Instituciones Privadas Similares. Gaceta Oficial de la República de Venezuela $N^{\circ} 3574$ (Extraordinario). 21-06-85. Caracas.

República de Venezuela. Presidente de la República (1999). Decreto con rango y fuerza de Ley Orgánica de la Administración Central. Gaceta Oficial de la República de Venezuela $N^{\circ} 36850$. 14-12-1999. Caracas.

Revista de Derecho Público (1980) N03. Editorial Juridica Venezolana. Caracas.

Revista de Derecho Público (1989) N³8. Editorial Jurídica Venezolana. Caracas.

Sayagués, E. (1959). Tratado de Derecho Administrativo. T. 1. Martín Bianchi Altuna. Montevideo.

Viloria, E. (1983), "Las Formas Jurídicas de las Empresas Públicas". Revista de Derecho Público. $N^{\circ} 14$. Editorial Juridica Venezolana. Caracas. 